\title{
Breast Mass in a Rubens Painting
}

\author{
Davide Lazzeri, M.D., ${ }^{1 *}$, Donatella Lippi, Ph.D. ${ }^{2}$, Manuel Francisco Castello, \\ M.D. ${ }^{1}$, and George M. Weisz, M.D., M.A. ${ }^{3,4}$ \\ ${ }^{\prime}$ Plastic Reconstructive and Aesthetic Surgery, Villa Salaria Clinic, Rome, Italy; ${ }^{2}$ Center for Medical \\ Humanities, Department of Experimental and Clinical Medicine, University of Florence, Italy; ${ }^{\circ}$ School of \\ Humanities, University of New England, Armidale, NSW, Australia; and ${ }^{4}$ School of Humanities, \\ University of New South Wales, Sydney, Australia
}

\begin{abstract}
Deformity of the breast and axilla observed in famous paintings is a fascinating field for the medico-artists. The attempt of a retrospective diagnosis of breast tumors is highly challenging. This paper deals with a Rubens painting portraying the heroine Judith with a visible but previously unreported left breast mass. Though speculative, the present medico-artistic diagnosis is of a tumor likely to be of benign nature. It is of interest that the present case is the sixth breast disease discovered in Rubens's works.
\end{abstract}

KEY WORDS: Baroque, breast mass, medico-artistic, Rubens

\section{INTRODUCTION}

The increasing realism pursued by artists following the Renaissance revolution has made observers today expect art works to be truthful. Depiction of certain deformities was always present due to the artists' styles in reproducing human figures. A medical diagnosis within the artistic field, such as those discussed in this paper, and in the referenced ones, ${ }^{1-4}$ can only be provided by direct visual evaluation, rarely assisted by technological tools. Such diagnosis remains presumptive, unless a written document presents a description and the intention of the painter. 4
Peter Paul Rubens belongs to the Baroque movement. He fully embraced the philosophy of extreme realism in portraits representing biblical or mythological female bodies, including breasts. They represent particular interest in the detection of breast tumors. ${ }^{1,3}$ A portrait dated 1617 constitutes the subject of this paper, with particular focus on the model's left breast.

\section{THE PAINTING}

The story of Judith and Holofernes is given in the deutero-canonical "Book of Judith" and is a recurrent topic in Renaissance and Baroque paintings

Citation: Lazzeri D, Lippi D, Castello MF, Weisz GM. Breast Mass in a Rubens Painting. Rambam Maimonides Med J 2016;7 (2):eo016. doi:10.5041/RMMJ.10243

Copyright: (C) 2016 Lazzeri et al. This is an open-access article. All its content, except where otherwise noted, is distributed under the terms of the Creative Commons Attribution License (http://creativecommons.org/licenses/by/3.0), which permits unrestricted use, distribution, and reproduction in any medium, provided the original work is properly cited.

Conflict of interest: No potential conflict of interest relevant to this article was reported.

* To whom correspondence should be addressed. E-mail: davidelazzeri@gmail.com 
(Figure 1). Judith was a beautiful chaste widow, coming from Bethulia. The city was besieged by the Assyrian army guided by Holofernes, who had fallen in love with Judith. She entered the General's tent, overcame him with drink, and decapitated Holofernes. Her facial expression is of hatred and disgust, and the image, although aesthetic, is quite violent.

In this painting Rubens depicted Judith's left breast with a lump involving the upper lateral quadrants, extending toward the subclavicular and axillary areas (Figure 2). No skin discoloration or ulceration is present, no redness or swelling is visible, the tumor is soft, multi-loculated, with nonretracted skin, and no skin surface alteration or hematoma signs are present. The nipple-areola complex is not visible.

\section{DISCUSSION}

Because of Rubens's high reputation, an inaccurate depiction of the model would be unlikely. Indeed, a breast mass would not have been intentionally drawn. In accordance with Rubens's pursuit of realism, it is our opinion that he realistically painted the mass in the model's breast. The attempt of a retrospective diagnosis of breast tumors in classic paintings is highly challenging. There are four aspects commonly raised in establishing a diagnosis. ${ }^{1-3,5}$

\section{Existent Imaging}

We observe that the breast tumor is soft, lobulated, irregular at the margins, with no skin retraction, no skin surface discoloration, nor "peau d'orange" present. Visually it does not correspond with infection or traumatic hematoma, it is not uniform, it is with irregular margins, and it does not have the features of a malignancy.

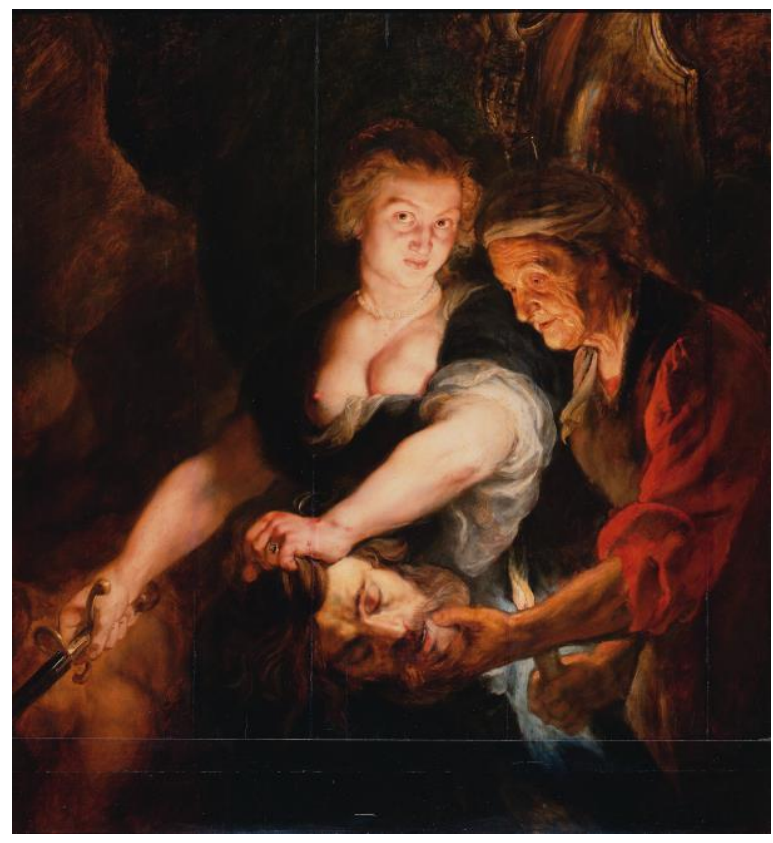

Figure 1. Judith with the Head of Holofernes (Book of Judith 13:11), Peter Paul Rubens (1617), oil on panel, $120 \times 111 \mathrm{~cm}(47.2 \times 43.7 \mathrm{in})$.

On display at the Herzog Anton Ulrich-Museum, Kunstmuseum des Landes Niedersachsen, Braunschweig, Germany. Peter Paul Rubens [Public domain], via Wikimedia Commons.

\section{The Artist's Intention}

An intentional, rather than inadvertent inclusion of a deformed breast in a beautiful woman (likely the muse or the lover of the painter himself) makes no sense. Why would the painter not include a perfect model? Why wouldn't he replace, if recognized, a "sick" image with a "healthy" representation?
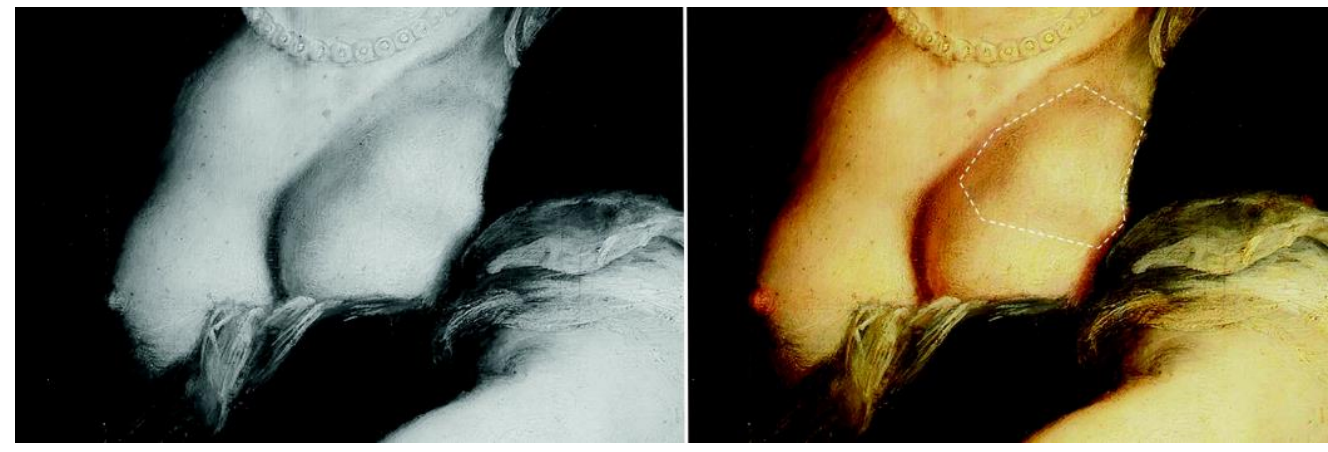

Figure 2. Close-up of Figure 1.

Left: The mass is highlighted in the grey scale pattern. Right: the boundaries of the mass are identified by the dotted white line. 


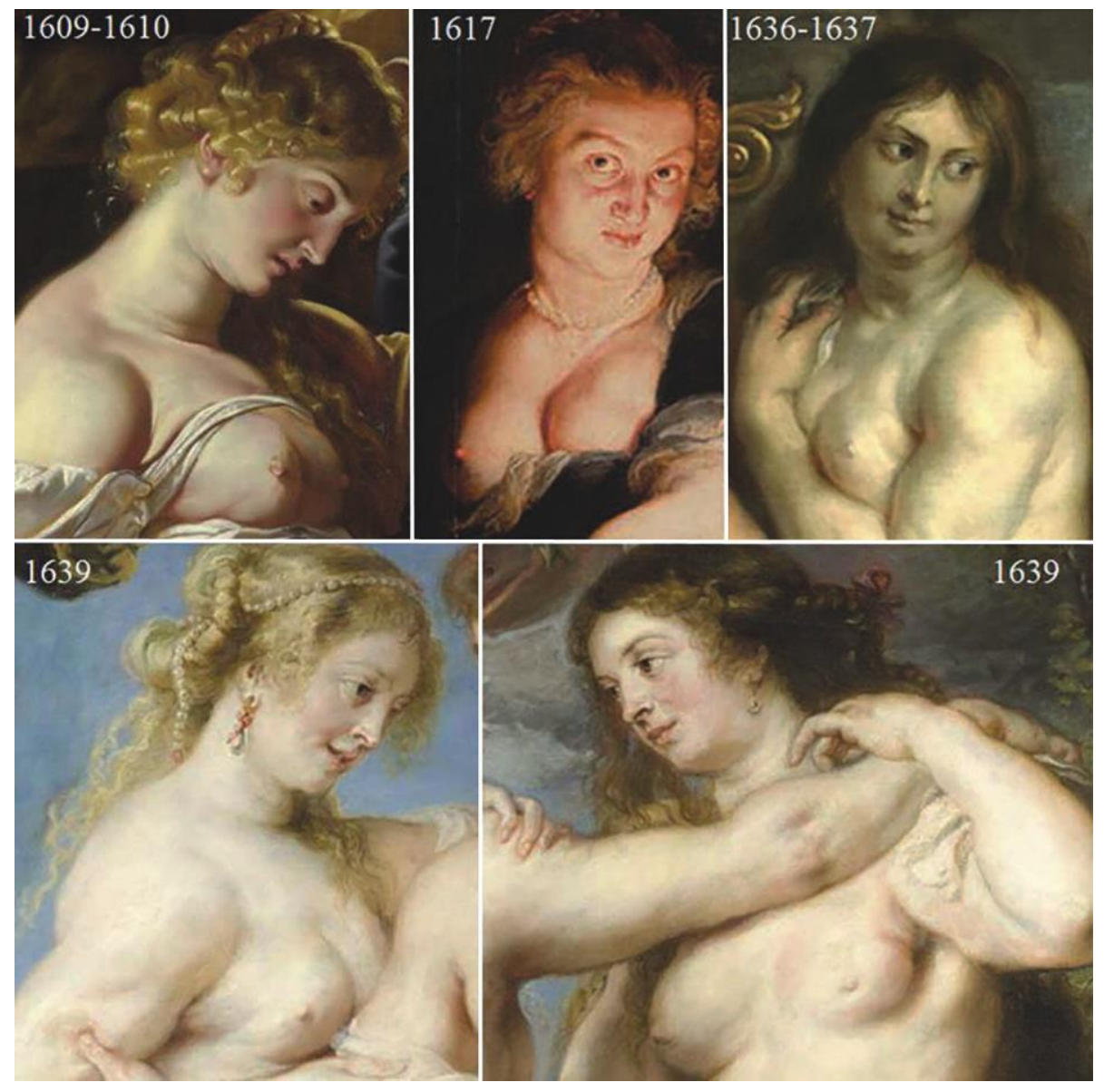

Figure 3. A collation of all models depicted by Rubens in which breast diseases have been recognized.

Top left: Detail of Samson and Delilah, Peter Paul Rubens (1609-10), oil on wood, $205 \times 185 \mathrm{~cm}(81 \times 73$ in). On display at the National Gallery, London, UK. Peter Paul Rubens [Public domain], via Wikimedia Commons.

Top center: Detail of Judith with the Head of Holofernes, Peter Paul Rubens (1617), oil on panel, $120 \times 111 \mathrm{~cm}$ (47.2×43.7 in). On display at the Herzog Anton Ulrich-Museum, Kunstmuseum des Landes Niedersachsen, Braunschweig, Germany.

Top right: Detail of Orpheus and Eurydice, Peter Paul Rubens (1636-7), oil on canvas, $245 \times 194 \mathrm{~cm}(96.4 \times 76.3$ in). On display at the Kunsthaus, Zürich, Switzerland. Peter Paul Rubens [Public domain], via Wikimedia Commons.

Bottom: The left Grace (left) and the right Grace (right) of The Three Graces, Peter Paul Rubens (1639), oil on canvas, $221 \times 181 \mathrm{~cm}(87 \times 71 \mathrm{in})$. On display at the Prado Museum, Madrid, Spain. Peter Paul Rubens [Public domain], via Wikimedia Commons.

\section{Differential Diagnosis}

Uncommon breast conditions such as Mondor's disease $^{3}$ or mammary deformities with typical aspects of malignancy have been previously detected in Rubens's paintings involving two of his Three Graces, Delilah, Eurydice, and Diana pursued by the satyr. ${ }^{1}$ Despite the visible difference with the benign tumor herein reported, these findings confirm the familiarity of Rubens in the depiction of his models' breasts and his extreme realism. There is no known written diagnosis in any of the Rubens portrayed cases, including in this "Judith with the Head of Holofernes." 1,2 Indeed, we have no way to correlate the depicted image with clinical signs. Our diagnosis is of benign disease, with a differential diagnosis among giant cyst, fibrocystic disease, giant fibroadenoma, adenosis, phyllodes tumor, hamartoma, lipoma, hemangioma, adenomyoepithelioma, neurofibroma, and pseudoangiomatous stromal hyperplasia. 


\section{Recognition of the Model}

A collation of all the models depicted by Rubens in which breast diseases have been recognized (Figure 3) does not allow any clear identification of the sitter of the portrait here referenced.

Art historians give credit to the theory that the Fourment sisters were used as models.3,6 Hélène Fourment (the second wife of Rubens) served partly as the model for numerous portraits, including the left Grace. She was born in 1614, and her sister Susana in 1599, so we should exclude that Rubens used his second wife or his sister-in-law as models for the Judith.

Instead, the first wife of Rubens, Isabelle Brant, has facial features similar to the Judith (Figure 4). She died in 1629 of plague 12 years after the Judith depiction, an event that would support our theory about the benign nature of the mass. There is no portrait other than Figure 4 (right) in which the breast of Isabelle may be evaluated. Rubens or his contemporary art historians did not leave any written documents that could contribute in this debate.

\section{CONCLUSION}

Mammary deformities observed in famous paintings represent a fascinating field of the medico-artistic diagnosis. The discussion is ongoing with lots of controversies. The present investigation deals with a painting in which the sitter shows a breast mass, visually assessed as being of a benign nature. This medico-artistic diagnosis is speculative, but likely correct. It is of interest that the present case is the sixth breast disease discovered in Rubens's works.

\section{REFERENCES}

1. Grau JJ, Estapé J, Diaz-Padrón M. Breast cancer in Rubens paintings. Breast Cancer Res Treat 2001;68: 89-93. Full Text

2. Grau JJ, Estrach T. Old masters as clinical photographers: multifocal breast cancer diagnosed 400 years ago. Breast Cancer Res Treat 2008;111:11-13. Full Text

3. King B, Shortis A, King AJ. Did Rubens' Delilah have Mondor's disease? ANZ J Surg 2013;83:146-8. Full Text

4. Weisz GM, Albury WR. The medico-artistic phenomenon and its implications for medical education. Med Hypotheses 2010;74:169-73. Full Text

5. Gross A. An epidemic of breast cancer among models of famous artists. Breast Cancer Res Treat 2004;84: 293. Full Text

6. Dequeker J. Benign familial hypermobility syndrome and Trendelenburg sign in a painting "The Three Graces" by Peter Paul Rubens (1577-1640). Ann Rheum Dis 2001;60:894-5.

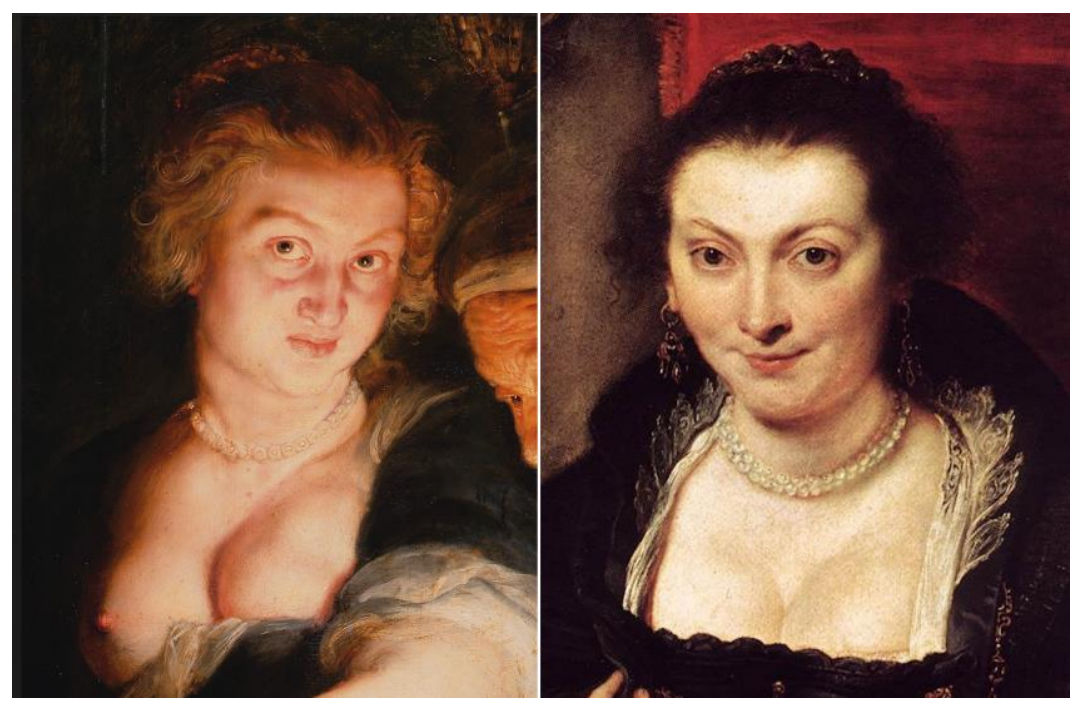

Figure 4. A Comparison between the Judith with the Head of Holofernes (left) and the Portrait of Isabella Brant (right) by Rubens (c.1625), oil on canvas.

On display at the Galleria degli Uffizi, Florence, Italy. Portrait of Isabella Brant by Peter Paul Rubens [Public domain], via Wikimedia Commons. 